\title{
НАЛОГОВОЕ АДМИНИСТРИРОВАНИЕ ГИБРИДНЫХ ФИНАНСОВЫХ ИНСТРУМЕНТОВ
}

\section{TAX ADMINISTRATION OF HYBRID FINANCIAL INSTRUMENTS}

\section{Ayrapetyan}

Summary. The purpose of this article is to determine specialties of tax administration of hybrid financial instruments. Due to their cross-border hybrid nature hybrid financial instruments require special approach to control by tax authorities. From theoretical point of view it is important to understand, whether tax administration of hybrid financial instruments should comply with some special principle that is not typical for administration of any other tax object. If yes, what such principle should be about? Other important question is how a set of tax administration tools should be composed and in what order used to fit mostly the economic substance of hybrid financial instruments. Author suggests special principle of segmented approach to tax control of transactions with financial instruments and, in compliance with it, outlines target set of tax administration tools and algorithm of their application to hybrid financial instruments.

Keywords: hybrid financial instruments, tax administration, tax administration principles, international exchange of information.
B 2015 году в рамках Плана Организации экономического сотрудничества и развития (далее ОЭСР) по борьбе с размыванием налоговой базы и выводом прибыли из-под налогообложения (Action Plan on Base Erosion and Profit Shifting) [1] был опубликован отчет «Neutralising the Effects of Hybrid Mismatch Arrangements», посвященный, в том числе вопросам нейтрализации негативных эффектов гибридных финансовых инструментов, используемых для уклонения от налогообложения.

Под гибридными финансовыми инструментами ОЭСР понимает финансовые инструменты, в основе построения, которых используются отличия в их налоговой классификации в соответствии с законодательством двух или более государств, результатом чего становится двойное неналогообложение доходов, в том числе долгосрочное отложенное налогообложение [2]. Международное двойное неналогообложение, согласно ОЭСР, заключается в уменьшении налоговой базы плательщика дохода и не включении дохода в налоговую базу его получателя.

\author{
Айрапетян Левон Камоевич \\ Аспирант, Финансовый университет при \\ Правительстве РФ, г. Москва \\ levonayrapetyan@gmail.com
}

Аннотация. Целью данной статьи является определение особенностей налогового администрирования гибридных финансовых инструментов. В силу своего трансграничного гибридного характера гибридные финансовые инструменты требуют специального подхода к контролю со стороны налоговых органов. С теоретической точки зрения важно определить, должно ли налоговое администрирование гибридных финансовых инструментов соответствовать некоему специальному принципу, не характерному для администрирования налогообложения иных объектов. Если да, то в чем именно должен заключаться подобный принцип? Другим важным вопросом является то, какими должны быть конкретный состав инструментов налогового администрирования и последовательность их применения для наибольшего соответствия экономической сущности гибридных финансовых инструментов. Автор предлагает специальный принцип сегментированного подхода к налоговому контролю операций с финансовыми инструментами и, в соответствии с ним, выделяет целевой состав инструментов налогового администрирования и алгоритм их применения к гибридным финансовым инструментам.

Ключевые слова: гибридные финансовые инструменты, налоговое администрирование, принципы налогового администрирования, международный обмен информацией.

Тот факт, что гибридные финансовые инструменты классифицируются по-разному в разных странах, а также проистекающий из этого факт, что они могут быть заключены только между налоговыми резидентами двух разных стран, приводит к тому, что применение к ним общих инструментов налогового администрирования в общем порядке не позволяет налоговым органам системно и в полной мере контролировать отсутствие международного двойного неналогообложения доходов по таким инструментам. Это обуславливает необходимость специального методического подхода к их налоговому администрированию.

Первым шагом в определении особенностей методического подхода к налоговому администрированию гибридных финансовых инструментов является проверка гипотезы о том, что названный подход должен соответствовать специальному принципу, соблюдение которого не требуется в обязательном порядке в отношении иных объектов налогообложения (например, обычных негибридных финансовых инструментов). 
Вторым шагом является определение состава инструментов налогового администрирования гибридных финансовых инструментов и порядка их применения налоговыми органами. Необходимо установить такую комбинацию инструментов, которая бы в наибольшей степени соответствовала экономической сущности гибридных финансовых инструментов и позволяла налоговым органам осуществлять результативный контроль за отсутствием двойного неналогообложения.

Итак, задаваясь вопросом о необходимости особого принципа налогового администрирования гибридных финансовых инструментов, определим к какой группе объектов налогообложения относятся такие инструменты.

Гибридный характер финансовых инструментов сводится к комбинированию в рамках одного договора как признаков долгового обязательства, так и долговой инвестиции. Так, анализ различных определений гибридных финансовых инструментов в дополнение к вышеприведенной трактовке ОЭСР позволяет определить гибридные финансовые инструменты с экономической точки зрения как структурированные и не структурированные мезонинные финансовые инструменты [4, С. 124134]. Из данного определения, а также того факта, что классификация гибридных финансовых инструментов для целей налогообложения в разных странах разная, следует, что такие финансовые инструменты в конкретной стране принимают либо статус сугубо долгового инструмента, либо сугубо долевого. Таким образом, можно говорить о том, что гибридные финансовые инструменты с точки зрения их квалификации для целей налогообложения изначально попадают в более широкую категорию - финансовые инструменты. Безусловно, при наличии в стране специального порядка налогообложения гибридных финансовых инструментов они становятся самостоятельным выделенным объектом налогообложения, но даже в этой ситуации при недобросовестном поведении налогоплательщика (сокрытии гибридного характера финансового инструмента) гибридные финансовые инструменты вновь оказываются частью общей категории - финансовые инструменты. Во избежание разночтений, необходимо отметить, что в данной статье под финансовыми инструментами понимаются договоры, на доходы и расходы, по которым распространяются положения о налогообложении налогом на прибыль долговых обязательств, операций с ценными бумагами, долями, паями или операций с производными финансовыми инструментами.

Итак, с точки зрения налогового администрирования налоговые органы в ходе мероприятий налогового контроля могут обнаружить только совокупность финансовых инструментов, которая включается в себя как гибридные, так и не гибридные инструменты. При этом без дополнительных процедур у налоговых органов нет возможности отличить гибридные финансовые инструменты от негибридных. В связи с этим целесообразно рассмотреть принципиальное отличие гибридных и негибридных финансовых инструментов с точки зрения налогового администрирования.

Главное отличие заключается в том, что статус финансового инструмента как «гибридного» зависит от его квалификации для целей налогообложения в двух и более странах. В то же время не гибридные финансовые инструменты (например, договор обыкновенного займа) классифицируются одинаково в разных странах, в связи с чем для целей налогообложения и налогового администрирования в одной стране не имеет значения налоговая классификация в другой. Это принципиальное отличие, как будет продемонстрировано далее, имеет важное значение для налогового администрирования.

Неразрывная связь налоговых классификаций одного и того же гибридного финансового инструмента в разных странах обуславливает необходимость обмена информацией между их национальными налоговыми органами. Чтобы признать тот или иной финансовый инструмент гибридным налоговому органу необходимо получить информацию, во-первых, о том, что в другом государстве проверяемый финансовый инструмент квалифицирован иначе, а во-вторых, что отличия в квалификациях привели к международному двойному неналогообложению. В то же время, для финансовых инструментов, не относящихся к гибридным, подобное международное взаимодействие налоговых органов не требуется как обязательное условие осуществления налогового администрирования. Важно понимать, что международный обмен информацией является не инструментом, упрощающим налоговое администрирование гибридных финансовых инструментов, а является обязательным условием для возможности их налогового администрирования как такового.

Однако, возвращаясь к тезису о том, что гибридные финансовые инструменты изначально относятся к такой общей категории объектов налогообложения как «финансовые инструменты», можно выделить следующее препятствие в налоговом администрировании: налоговые органы не смогут запросить у иностранных налоговых органов информацию об иностранной налоговой квалификации всех трансграничных финансовых инструментов, заключенных налогоплательщиком, для их проверки на «гибридность». Невозможность такого подхода обусловлена высокими трудовыми и временными затратами на подобный обмен информацией, так как в рамках каждой налоговой проверки будут требоваться множественные запросы в налоговые органы разных 
государств, осуществляемые по регламентированным процедурам. В связи с этим, возникает обоснованная необходимость в разделении гибридных и не гибридных финансовых инструментов для целей налогового администрирования.

В свою очередь дифференциация гибридных и не гибридных финансовых инструментов может достигаться за счет поиска налоговыми органами в ходе мероприятий налогового контроля у всех трансграничных финансовых инстурментов налогоплательщика признаков гибридности. Несмотря на то, что налоговые органы, как было описано ранее, не могут сразу самостоятельно обнаружить заключенные налогоплательщиком гибридные финансовые инструменты, они могут осуществлять поиск неких характерных признаков, паттернов гибридных финансовых инструментов. О том, каким образом может быть сформирован список таких признаков, речь пойдет далее в настоящей статьей. Важно, что в результате подобного поиска характерных признаков налоговые органы смогут разделить общий пул финансовых инструментов на потенциально гибридные и не гибридные. Такое разделение послужит отправной точкой для дальнейшего сегментированного подхода к налоговому контролю операций с финансовыми инструментами: к гибридным финансовым инструментам будет применяться свой особый инструментарий налогового контроля, а к остальным не гибридным финансовым инструментам - общий инструментарий в общем порядке.

С теоретической точки зрения выделение сформулированного подхода на уровне принципа обусловлено двумя причинами. Во-первых, без дифференцированного подхода к налоговому контролю, контроль правомерности исчисления налоговой базы по операциям с гибридными финансовыми инструментами невозможен (обосновано выше необходимостью международного обмена информацией). Во-вторых, среди распространенных в мире налоговых правил, касающихся международного налогообложения (налогообложение контролируемых иностранных компаний, требование о наличии фактического права на доход, налогообложение доходов фискально-прозрачных организаций, правила трансфертного ценообразования, критерии налогового резидентства, налогообложение гибридных финансовых инструментов и т.п.), только для налогового контроля гибридных финансовых инструментов международный обмен информацией между налоговыми органами является обязательным. Для других перечисленных налоговых правил международный обмен информацией может упрощать, ускорять или иным образом повышать эффективность налогового контроля, но не является обязательным элементом, без которого налоговый контроль невозможен. Таким образом, подтверждается гипотеза о том, что методический подход к налоговому админи- стрированию гибридных финансовых инструментов должен соответствовать специальному принципу, соблюдение которого не требуется в обязательном порядке в отношении иных объектов налогообложения.

Для формирования методического подхода к налоговому администрированию гибридных финансовых инструментов, прежде всего важен состав инструментов налогового администрирования и порядок их применения налоговыми органами, которые бы в наибольшей степени соответствовали экономической сущности гибридных инструментов. Предпримем попытку сформировать перечень применимых инструментов, отталкиваясь от каждой особенности гибридного финансового инструмента в отдельности.

Первая особенность состоит в том, что гибридный финансовый инструмент в конкретной стране получает налоговую квалификацию как сугубо долгового или долевого инструмента, в связи с чем налоговые органы не могут самостоятельно отделить гибридные финансовые инструменты от не гибридных. Инструмент налогового администрирования (частью которого является налоговый контроль) [5], который может помочь налоговым органам преодолеть трудности в идентификации гибридных финансовых инструментов, уже был назван ранее в данной статьей: поиск характерных признаков гибридных финансовых инструментов у всех заключенных налогоплательщиков трансграничных финансовых инструментов. Для использования такого инструмента налоговым органам потребуется заранее сформировать список признаков гибридности. Основой для подобного списка может быть, во-первых, отечественная судебная практика о переквалификации долговых финансовых инструментов в долевые, во-вторых, иностранная судебная практика по вопросам налогообложения гибридных финансовых инструментов, в-третьих, анализ публичных проспектов эмиссии ценных бумаг, совмещающих в себе признаки долга и капитала. Поиск налоговыми органами признаков гибридности для выявления потенциально гибридных финансовых инструментов в целом соответствует текущей тенденции к риск-ориентации налогового контроля. По мнению ФНС России применение риск-ориентированного подхода при планировании выездных налоговых проверок обусловлено необходимостью снижения административной нагрузки на бизнес, сокращением финансовых издержек для субъектов хозяйственной деятельности при одновременном повышении эффективности государственного контроля и обеспечении соблюдения действующего законодательства [6]. Несмотря на то, что предлагаемый инструмент налогового контроля относится не к планированию налоговых проверок, а непосредственно к ходу самой проверки, представляется, что большая часть преимуществ риск-ориентированно- 
го подхода, приводимых ФНС России, применима и к поиску признаков гибридности.

Вторая особенность гибридных финансовых инструментов заключается в том, что международное двойное неналогообложение доходов по ним возникает в силу налоговых последствий в двух странах, налоговыми резидентами которых являются стороны договора. С точки зрения налогового администрирования это означает, что, выявив потенциально гибридные финансовые инструменты на первом этапе, на втором этапе потребуется получение от иностранного налогового органа информации, которая бы подтверждала или опровергала статус гибридного финансового инструмента. В данном контексте применимым инструментом налогового контроля является международный обмен информацией по запросу. У иностранных налоговых органов может запрашиваться информация о том, является ли в принципе рассматриваемый договор финансовым инструментом по иностранному налоговому законодательству, какова конкретная квалификация дохода/расхода в иностранном государстве, правомерно ли учел/не учел иностранный налогоплательщик выплаты по договору в своей налоговой базе, в какой сумме. Ответы на данные вопросу позволят налоговым органам, сделать вывод о том, является ли проверяемый финансовый инструмент гибридным, в какой конкретно сумме возникло международное двойное неналогообложение. Далее налоговые органы смогут сравнить полученную информацию с тем, каким образом налогоплательщик учел доходы/расходы по проверяемому финансовому инструменту в своей налоговой базе, и оценить правомерность действий налогоплательщика.

Однако помимо инструментов налогового контроля, используемых непосредственно в ходе контрольных мероприятий, для снижения объема проверяемых финансовых инструментов в ходе налоговых проверок целесообразно наличие некоего предварительного инструмента налогового администрирования. Такой предварительный инструмент может возлагать дополнительную обязанность на самих налогоплательщиков. Так, по аналогии с российскими правилами трансфертного ценообразования, в соответствии с которыми налогоплательщик обязан подавать в налоговые органы уведомления о контролируемых сделках [3], на налогоплательщика может быть возложена обязанность об уведомлении налогового органа о заключенных гибридных финансовых инструментах. Альтернативно, в существующие формы уведомления о контролируемых сделках может быть добавлен раздел с указанием на то, является ли заключенный финансовый инструмент гибридным. Аналогия с контролируемыми сделками справедлива в особенности потому, что ОЭСР предлагает распространять действие специального порядка налогообложения гибридных финансовых инструментов на сделки между взаимозависимыми лицами [2]. В очередности применения инструментов налогового администрирования гибридных финансовых инструментов получение уведомлений от налогоплательщиков занимает первое место, так как предшествует непосредственно мероприятиям налогового контроля. Также у предлагаемого обязательного уведомления налоговых органов есть преимущество в более широком понимании налогового администрирования - с течением времени массив полученных уведомлений станет источником статистических данных о распространенности гибридных финансовых инструментов в стране, наиболее часто используемых видах инструментов и т.п.

Три представленных выше инструмента налогового администрирования относятся непосредственно к налоговому контролю. Однако нельзя забывать о более широком содержании налогового администрирования. Так как специальный порядок налогообложения гибридных финансовых инструментов вплоть до 2015 года существовал далеко не во все странах, и только после публикации в 2015 году ОЭСР отчета «Neutralising the Effects of Hybrid Mismatch Arrangements» страны начали постепенно вводить новые налоговые правила, можно предположить, что для многих налогоплательщиков в целом данное явление является новым и малознакомым. Неопределенность для налогоплательщиков усиливается еще и тем, что для соблюдения специальных правил налогообложения гибридных финансовых инструментов необходимо знать налоговое законодательство иностранных государств, уметь его анализировать. Безусловно налоговые органы не могут снять неопределенность в полном объеме, однако целесообразным и возможным представляется размещение налоговыми органами в сети Интернет следующей не обладающей юридической силой пояснительной информации:

- разъяснения о механизме функционирования и целях введения новых правил по налогообложению гибридных финансовых инструментов в своей стране;

- не конфиденциальная информация, полученная локальным налоговым органом от иностранных, которая может быть полезна локальным налогоплательщикам для соблюдения антигибридных правил (например, описание основных параметров иностранных антигибридных правил, база данных о квалификации основных видов финансовых договоров в соответствии с налоговым законодательством иностранных государств и т.п.).

Предоставление налогоплательщикам пояснительной информации может осуществляться непрерывно, вне связи с мероприятиями налогового контроля, в связи с чем в последовательности применения инструмен- 
тов налогового администрирования гибридных финансовых инструментов оно занимает особое место.

По итогам проведенного анализа сформулирован специальный для гибридных финансовых инструментов принцип сегментированного подхода к налоговому контролю операций с финансовыми инструментами, который заключается в обязательном поиске в ходе мероприятий налогового контроля у всех финансовых инструментов признаков гибридности с последующим разделением финансовых инструментов для целей налогового контроля на потенциально гибридные и не гибридные. Названный принцип позволяет выделять гибридные финансовые инструменты в отдельную группу для целей дальнейшего применения к ним особого порядка налогового контроля. Более того, обоснована необходимость выделения указанного принципа: налоговый контроль сделок с гибридными финансовыми инструментами путем сплошной проверки всех заключенных финансовых инструментов с использованием информационного обмена с иностранными налоговыми органами чрезвычайно затратен с точки зрения времени и трудовых ресурсов, что фактически приводит к невозможности осуществления налогового контроля.

В части методического подхода выделен состав инструментов налогового администрирования, наиболее соответствующий особенностям налогового администрирования гибридных финансовых инструментов, в том числе выделенному принципу сегментированного подхода, а также определен алгоритм их применения: систематическое получение налоговыми органами от налогоплательщиков информации о наличии/отсутствии гибридного характера у заключенных ими финансовых инструментов (первый этап налогового контроля), использование в ходе мероприятий налогового контроля таких инструментов как поиск заранее определенных признаков гибридных финансовых инструментов (второй этап налогового контроля) и международный обмен информацией по запросу (третий этап налогового контроля), и непрерывное предоставление налогоплательщикам пояснительных и справочных материалов о локальных и иностранных антигибридных правилах (применяется постоянно вне рамок налогового контроля).

\section{ЛИТЕРАТУРА}

1. Action Plan on Base Erosion and Profit Shifting // Официальный сайт 0ЭCP URL: https://www.oecd.org/ctp/BEPSActionPlan.pdf

2. Neutralising the Effects of Hybrid Mismatch Arrangements // Официальный сайт 0ЭCP URL: http://www.oecd-ilibrary.org/docserver/download/2315291e.pdf?ex pires $=1491681774 \&$ id $=$ id\&accname $=$ guest $\&$ checksum $=$ CD1D7C3093F8B3B71BA745C56FA8A355

3. Налоговый кодекс Российской Федерации (часть первая) от 31.07.1998 N146-Ф3 (ред. от 27.12.2019) (с изм. и доп., вступ. В силу с 01.01.2020)

4. Л.К. Айрапетян. Предпосылки возникновения и распространения гибридных финансовых инструментов. Экономика: вчера, сегодня, завтра. - 2019. Том 9. № 7А. — С. 124-134.

5. Л.И. Гончаренко. К вопросу о понятийном аппарате налогового администрирования // Налоги и налогообложение, 2010, № 2

6. Риск-ориентированный подход при проведении выездных налоговых проверок // Официальный сайт ФHC Роcсии URL: https://www.nalog.ru/rn38/about_ $\mathrm{fts} / \mathrm{knd} / 4 \mathrm{kv} 18 / 8213131 /$ 